\title{
The effect of piezoelectric surgery implant osteotomy on radiological and molecular parameters of peri-implant crestal bone loss: a randomized, controlled, split-mouth trial
}

\author{
Peker Tekdal, Gözde ; Bostanci, Nagihan ; Belibasakis, Georgios N ; Gürkan, Ali
}

\begin{abstract}
AIM: To evaluate the effect of piezoelectric surgery (PS) implant osteotomy on biochemical and radiological parameters of crestal bone (CB) loss. MATERIAL AND METHODS: In this randomized, controlled, clinical study, 38 osteotomies were prepared with PS and drilling in the posterior maxilla in a split-mouth design. Implants were placed and left for non-submerged healing. Osteotomy time, insertion torque, pain perception, probing depth, and modified gingival and plaque indices were recorded. Peri-implant sulcular fluid (PISF) was collected from four sites of each implant at 2, 4, 8, 12 , and 24 weeks. PISF samples were analyzed by ELISA for receptor activator of nuclear factor kappa-B-ligand (RANKL) and osteoprotegerin. CB loss was assessed on periapical radiographs at the 12 th and on cone beam computed tomography (CBCT) at the 24th weeks. The influence of time and osteotomy method on biochemical and radiological parameters of CB loss employed statistical method of Brunner-Langer. RESULTS: Osteotomy time for PS group was significantly longer than the drill group $(\mathrm{P}<0.05)$. Pain perception that was lower in the PS than in the drill group depended on osteotomy method $(\mathrm{P}<0.05)$. PS group had lower RANKL total amount than the drill group $(\mathrm{P}<0.05)$. Mean CB loss on periapical radiographs at the 12 th week for $\mathrm{PS}$ and drill groups were 0.11 and $0.18 \mathrm{~mm}$, respectively $(\mathrm{P}>0.05)$. At the 24th week, PS and drill groups showed 0.11 and $0.12 \mathrm{~mm} \mathrm{CB}$ losses on CBCT, respectively $(\mathrm{P}>0.05)$. However, $\mathrm{CB}$ loss values did not depend on osteotomy modality $(\mathrm{P}>0.05)$. CONCLUSION: PS may modify and reduce bone-destructive inflammatory response during implant osseointegration. Therefore, on the molecular level, it might be a less traumatic osteotomy modality than drilling although this was not reflected by CB loss values in the present study.
\end{abstract}

DOI: https://doi.org/10.1111/clr.12620

Posted at the Zurich Open Repository and Archive, University of Zurich ZORA URL: https://doi.org/10.5167/uzh-111621

Journal Article

Accepted Version

Originally published at:

Peker Tekdal, Gözde; Bostanci, Nagihan; Belibasakis, Georgios N; Gürkan, Ali (2016). The effect of piezoelectric surgery implant osteotomy on radiological and molecular parameters of peri-implant crestal bone loss: a randomized, controlled, split-mouth trial. Clinical Oral Implants Research, 27(5):535-544. DOI: https://doi.org/10.1111/clr.12620 
The effect of piezoelectric surgery implant osteotomy on radiological and molecular parameters of peri-implant crestal bone loss. A randomized, controlled, split-mouth trial

\author{
Gözde Peker Tekdal* \\ Nagihan Bostancl** \\ Georgios N. Belibasakis** \\ Ali Gürkan* \\ *Ege University, School of Dentistry, Department of Periodontology, Turkey \\ ** University of Zurich, Center of Dental Medicine, Institute of Oral Biology, Section of \\ Oral Microbiology and Immunology, Switzerland.
}

Corresponding author:

Assoc. Prof. Dr. Ali GÜRKAN

Ege University, School of Dentistry

Department of Periodontology

Bornova-35100, Izmir-Turkey

Fax: +902323880325

e-mail: ali.gurkan@ege.edu.tr

Running head: Piezoelectric implant osteotomy and crestal bone loss 


\begin{abstract}
Aim: To evaluate the effect of piezoelectric surgery (PS) implant osteotomy on biochemical and radiological parameters of crestal bone (CB) loss.

Materials and Methods: In this randomized, controlled, clinical study thirty-eight osteotomies were prepared with PS and drilling in the posterior maxilla in a splitmouth design. Implants were placed and left for non-submerged healing. Osteotomy time, insertion torque, pain perception, probing depth and modified gingival and plaque indices were recorded. Peri-implant sulcular fluid (PISF) was collected from 4 sites of each implant at $2^{\text {nd }}, 4^{\text {th }}, 8^{\text {th }}, 12^{\text {th }}$ and $24^{\text {th }}$ weeks. PISF samples were analyzed by ELISA for receptor activator of nuclear factor kappa-Bligand (RANKL) and osteoprotegerin (OPG). CB loss was assessed on periapical radiographs at $12^{\text {th }}$ and on cone beam computed tomography (CBCT) at $24^{\text {th }}$ weeks. The influence of time and osteotomy method on biochemical and radiological parameters of $\mathrm{CB}$ loss employed statistical method of BrunnerLanger.
\end{abstract}

Results: Osteotomy time for PS group was significantly longer than the drill group $(p<0.05)$. Pain perception that was lower in the PS than the drill group depended to osteotomy method ( $p<0.05$ ). PS group had lower RANKL total amount than the drill group $(\mathrm{p}<0.05)$. Mean $C B$ loss on periapical radiographs at $12^{\text {th }}$ week for PS and drill groups were $0.11 \mathrm{~mm}$ and $0.18 \mathrm{~mm}$, respectively ( $p>0.05)$. At $24^{\text {th }}$ week PS and drill groups showed $0.11 \mathrm{~mm}$ and $0.12 \mathrm{~mm} \mathrm{CB}$ loss on $C B C T$, respectively ( $p>0.05$ ). However, $C B$ loss values did not depend on osteotomy modality ( $p>0.05)$.

Conclusion: PS may modify and reduce bone-destructive inflammatory response during implant osseointegration. Therefore, it might be a less traumatic osteotomy modality than drilling although this was not reflected by CB loss values in the present study.

Key Words: Dental Implant, Piezoelectric Surgery, Osteotomy, RANKL, OPG 


\section{Introduction}

Preservation of crestal bone (CB) level around implants is a pivotal issue that dictates both biological and esthetic long-term success (Anibali et al.2012, Papasdyrikos et al. 2012). CB level around implants is substantially modeled at an early period of time, in-between placement of implants and 1 year after prosthetic loading (Tatarakis et al. 2012, Oh et al. 2002). This phenomenon that occurs as a result of various local and systemic factors, is called early bone loss. In the following periods of implant function CB modelling is minimal around a successful implant. Parallel to advancing implant technology and increasing esthetic demands clinicians expect to maintain $C B$ and to minimize or prevent $C B$ loss occurring at early periods of implant function (Papasdyrikos et al. 2012, Anibali et al. 2012). Early CB loss is a multifactorial entity including factors related to patient, implant design, prosthetic interventions and surgery which are generally modifiable or avoidable (Oh et al. 2002, Tatarakis et al. 2012, Capelli 2013).

The method utilized in preparation of implant osteotomy is one of the several surgical factors that may affect early CB loss (Padmanabhan \& Gupta 2010, Shayatesh et al. 2013). Conventional implant osteotomy is prepared with drill sets, which are specifically structured to the needs of the relevant implant design. Drilling with sharp drills in the appropriate order under copious irrigation is of primary importance to preserve $C B$, since trauma resulting from increased pressure and heat may lead to compromised healing and consequently to CB loss (Tatarakis et al. 2012). Piezoelectric surgery (PS) has been introduced as a valuable alternative to avoid disadvantages associated with the traditional rotating instruments (Schlee et al. 2006, Maurer et al. 2008). PS has been advocated to make precise, safe, less traumatic cuts thus allowing increased osteogenic potential, less edema, better wound healing, decreased presence of microfractures and smear layer than rotating instruments (Maurer et al. 2008, Chiriac et al. 2005, Trisi et al. 2011, Schütz et al. 2012, Rashad et al. 2011, Baker et al. 2012, Claire et al. 2013). Intraoperative advantages of this technique are 
selective hard tissue cuts without damage to soft tissues and better visualization with profuse irrigation (Pavlikova et al. 2011, Schlee et al. 2006). Having these beneficial features, PS-assisted osteotomies may be preferred in intraoral hardtissue surgical procedures such as maxillary sinus lifting, autologous bone graft harvesting, bone splitting, lateralization of the inferior alveolar nerve, atraumatic tooth extraction, root resection and implant site preparation (Pavlikova et al. 2011).

Current PS systems offer clinicians tip sets with varying design, to be used for creation of an implant recipient site. Previous ex-vivo, experimental and clinical studies have reported on the efficacy of PS in implant site preparation. It has been shown that implant site osteotomy with PS generates more heat than conventional driling but with sufficient irrigation this tendency can be reduced to normal limits (Rashad et al. 2011). In some animal studies comparable osseointegration process, bone to implant contact, trabecular bone volume and structure has been demonstrated in histological sections obtained from sites prepared with drill or PS (Bengazi et al. 2012, Kfouri et al. 2013, Estevez et al. 2013). In contrast, less inflammatory cells, microcracks and bone debris, earlier increase in expression of bone morphogenetic protein-4 and transforming growth factor- $\beta 2$ and faster new bone formation in comparison to drilling has been reported for PS (Preti et al. 2007, Trisi et al. 2011).

Previous clinical studies regarding PS implant bed preparation efficacy have predominantly focused on stability changes and implant survival. In these studies comparison of drill and PS osteotomies revealed greater ISQ values, limited decrease of ISQ values and an earlier shifting from a decreasing to an increasing stability pattern and high and comparable survival rates in favor of PS (Canullo et al. 2013, Stacchi et al. 2013, Neto et al. 2013, Vercelotti et al. 2014). Furthermore, a clinical densitometric study revealed higher bone density around implants inserted following PS osteotomy than observed around implants inserted following rotatory protocols (Alberti et al. 2010).

Despite extensive clinical use and documented efficacy of PS as an osteotomy system, the data derived from increasing number of studies published 
to date does not provide an answer on its effectiveness over the conventional implant osteotomy systems with respect to CB loss. Although one recent controlled study reported periimplant CB loss values following mixed drilling/PS osteotomy (Canullo et al. 2013), data regarding CB level changes around implants placed into sites that all osteotomy sequences were performed with PS tips is lacking. Given the beneficial features of PS, the present study was based on the hypothesis that preparing the entire implant osteotomy with consecutive PS tips may cause less surgical trauma and better healing than drills which eventually may reduce osteotomy-related early $C B$ loss. Therefore, the aim of this clinical controlled trial was to comparatively evaluate the effect of PS and conventional drill osteotomy on biochemical and radiological parameters of periimplant $C B$ loss. The biochemical parameters included in particular the receptor activator of nuclear factor kappa-B-ligand (RANKL) and osteoprotegerin (OPG) molecular system, which is responsible for controlling the cellular events governing physiological or pathological bone resorption (Belibasakis \& Bostanci 2012).

\section{Materials and Methods}

\section{Study population and design}

This research was designed as a prospective, controlled, randomized and split-mouth study and was carried out at Ege University School of Dentistry Department of Periodontology between May 2013 and February 2014. The procedures related to the study was reviewed and approved by Ethical Board of Ege University School of Medicine (2013/13-2.1/12). The study outline is summarized in Figure 1.

Non-smoker subjects who had symmetrical partial edentulism in the maxillary posterior regions were monitored for inclusion into the study. After obtaining medical and dental history, clinical evaluations including occlusion, interocclusal distances, parafunctions, endodontic and periodontal lesions and soft tissues surrounding the edentulous space were made. Mesio-distal and 
bucco-palatal dimensions of the edentulous space were measured with a caliper. Thickness of the mucosa over the edentulous site was measured by inserting a dental syringe needle coupled with a rubber stopper through the soft tissue and then measuring the distance to the tip of the needle with a digital caliper. Same procedure was repeated on the buccal and palatal aspects of the edentulous site in order to make a rough estimate of available bone width. Panoramic radiograms (Kodak 8000, Carestream Health Inc, Rochester, NY, ABD) taken with a $5 \mathrm{~mm}$ reference metal ball were evaluated for bone pathologies, vertical dimensions of the available bone and distances to anatomical structures. Following clinical and radiological evaluations and non-surgical periodontal therapy and/or oral hygiene instructions, the procedures of the study as well as prosthetic rehabilitation alternatives other than implant-supported restorations were explained to the subjects in detail. Subjects willing to participate signed informed consent form in line with Helsinki declaration and were enrolled according to the following inclusion criteria:

(a) Bilateral edentulism in the maxillary posterior region dating back more than 6 months, (b) sufficient bone height (distance between bone crest and maxillary sinus $>8 \mathrm{~mm}$ ) and width at the alveolar crest $(\geq 7 \mathrm{~mm})$ that would not necessiate bone augmentation or osteotom instrumentation, (c) at least $2 \mathrm{~mm}$ vestibular keratinized mucosa width and $3 \mathrm{~mm}$ mucosa thickness, (d) full-mouth plaque and bleeding scores $<20 \%$. Subjects who had systemic diseases, conditions or used medications having potential to impair surgery, bone and wound healing dynamics were excluded. In addition, subjects who were allergic to antibiotics and non-steroidal anti-inflammatory drugs and had bone height $<8 \mathrm{~mm}$, ridge and soft tissue deficiencies requiring augmentation procedures and endodontic or periodontal lesions neighbouring the edentulous sites were also excluded.

\section{Surgical procedures}

Surgical procedures were conducted to place $4.1 \mathrm{~mm}$ wide and $8 \mathrm{~mm}, 10 \mathrm{~mm}$ or $12 \mathrm{~mm}$ long, cylindirical, screw-type, two-piece, bone level implants with an anodized surface, $6^{\circ}$ morse-taper connection and switched platform design (Biodenta $^{\circledR}$, Bone Level Implant, Biodenta Swiss AG, Switzerland) into 
osteotomies prepared with conventional drills (drill group; control) on one side and with PS implant tips (piezosurgery group; test) on the contralateral side in a single session. Patients were instructed to use p.o $2 \mathrm{gr}$ amoxycline (Largopen ${ }^{\circledR}$ 1000 mg, Bilim Pharmaceuticals, Turkey) $1 \mathrm{~h}$ prior to surgery. Infiltration anesthesia was achieved by an injectable solution including $2 \%$ lidocaine and 1/100.000 epinephrine (Jetokain ${ }^{\circledR}$, Adeka Pharmaceuticals, Turkey). Extraoral and intraoral asepsis was achieved by $10 \%$ povidone iodine (Batticon ${ }^{\circledR}$, Adeka Pharmaceuticals, Turkey) and $0.2 \%$ chlorhexidine gluconate (Klorhex ${ }^{\circledR}$, Drogsan Pharmaceuticals, Turkey) rinse for 30 seconds, respectively.

Toss of a coin at the beginning of the surgery session by an independent examiner not involved in surgical or follow-up procedures designated the randomization of osteotomy methods to right or left sites. Right side was always the first operated site where the osteotomies were prepared with one of the randomly selected methods. Left side received the other osteotomy modality.

Following control of anesthesia, a midcrestal incision that advanced as sulcular incision to the mesial and distal midpoints of neighbouring teeth were made. First, the buccal flap was raised and after the thickness of the mucosa was measured with a Willams probe the palatal flap was also raised. Osteotomies were prepared with drills of the respective implant system in the drill group (Biodenta ${ }^{\circledR}$, Bone Level Implant, Biodenta Swiss AG, Switzerland) by advancing the $2.0 \mathrm{~mm}$ pilot drill to the planned depth followed by widening of the osteotomy to $2.5 \mathrm{~mm}, 2.8 \mathrm{~mm}$ and $3.5 \mathrm{~mm}$, respectively (Figure 2 ). In PS group pilot osteotomies were prepared with PS device (Piezonmaster ${ }^{\circledR}$, EMS SA, Switzerland) and its relevant tips (Swiss Instruments Surgery, Implant System, Switzerland) at a maximum power and irrigation setting. First, $1.15 \mathrm{~mm}$-wide initial tip was used along the predetermined depth to create a pilot osteotomy. Then the osteotomy was widened to a final diameter of $3.5 \mathrm{~mm}$ by using $1.95 \mathrm{~mm}, 2.5$ $\mathrm{mm}, 2.8 \mathrm{~mm}, 3.05 \mathrm{~mm}$ and $3.3 \mathrm{~mm}$ tips respectively (Figure 3). Intermediate diameters and final diameter, depth and direction of the osteotomies were controlled in both groups with drill try-ins, which also functions as parallelling pins. Bone taps or crestal drills were not used for final contouring in both groups. 
Time spent for the preparation of the osteotomies was recorded. Then $4.1 \mathrm{~mm}$ diameter implants were placed at crestal level by a torque-controlled handpiece at a speed of $15 \mathrm{rpm}$ in both groups. Following removal of transfer abutments, straight healing abutments were inserted, the flaps were secured with 5.0 polypropylene (Doğsan Surgical Sutures, Turkey) interrupted sutures and the implants were left for non-submerged healing.

\section{Postoperative clinical procedures}

Patients were instructed to rinse with $0.2 \%$ chlorhexidine gluconate (Klorhex, Pharmaceuticals, Turkey) for 2 weeks and to use $200 \mathrm{mg}$ of ibuprophene three times per day (Nurofen, Abdi İbrahim Pharmaceuticals, Turkey) for 1 week. They were also instructed to abstain from brushing the surgery site for 2 weeks and chewing on the transmucosal implant parts.

The patients determined the pain perception on a $100 \mathrm{~mm}$ visual analogue scale (VAS) on the day of surgery and 2 and 7 days following surgery. Postoperative complications including edema, bleeding and infection were determined on days 7 and 14 postoperatively. Flap closure and its continuity were evaluated on the same days by early healing index (EHI) (Wachtel et al. 2003), which had been originally used following regenerative procedures for intrabony defects. The sutures were removed at second week following the surgery.

\section{Clinical and biochemical procedures}

A single calibrated examiner performed all clinical measurements (GPT). Modified gingival (MGI) and plaque indices (MPI) were recorded on weeks 2, 4, 8, 12 and 24 from 4 points around each implant with an UNC 12 probe. Probing depth (PD) was measured on weeks 12 and 24 following surgery with an UNC 12 probe. Repeatability of the examiner for PD measurements was $k_{w}=0.88$, as revealed by weighted kappa analysis.

In all groups PISF samples were obtained from 4 aspects of implants by the same periodontist (GPT) on the weeks 2, 4, 8, 12 and 24 postoperatively. Prior to PISF sampling sites were isolated by cotton rolls and healing abutment surfaces were cleaned with a fiber carbon curette and air-dried gently. Paper 
strips (Periopaper, ProFlow, Amityville, NY, USA) were inserted $1 \mathrm{~mm}$ into the crevice and left in place for $30 \mathrm{~s}$. Care was taken to avoid mechanical injury. The PISF volume absorbed on each strip was then determined by means of an electronic impedance device (Periotron 8000, ProFlow, Inc., Amityville, NY, USA), and all four were pooled into a sterile polypropylene tube which was previously coded to ensure masking of the laboratory technician and kept at $-40^{\circ} \mathrm{C}$ until analysed. The readings from the Periotron 8000 were converted to volume $(\mu \mathrm{l})$ by reference to the standard curve. The collected PISF samples were eluted in $450 \mu \mathrm{l}$ phosphate buffer saline (PBS, $\mathrm{pH}$ 7.2) in the presence of EDTA-free protease inhibitor cocktail (Roche Applied Science, Rotkreuz, Switzerland) and centrifufed at $2000 \times \mathrm{g}$ for $15 \mathrm{~min}$, at $4^{\circ} \mathrm{C}$. The levels of sRANKL and OPG in the eluted PISF samples were determined by enzyme-linked immunosorbent assay (ELISA) kits, as per the manufacturer's instructions (Biovender R\&D, Brno, Czech Republic). The sensitivities of the two kits were $0.4 \mathrm{pmol} / \mathrm{l}$ and $0.03 \mathrm{pmol} / \mathrm{l}$, respectively

\section{Radiological assesments}

Cone-beam computerized tomography (CBCT) (Kodak 9000 3D, Practice Works, Inc., Atlanta, USA) was obtained on the day of surgery and was repeated at week 24 with $10.8 \mathrm{~s}$ exposure time, $70 \mathrm{Kv}$ and $10 \mathrm{~mA}$ settings. Dimensions of the isotropic voxels were $200 \mu \mathrm{m}$. Image analysis was performed by using a 3D software (CS 3D Imaging Software version 3.1.9 Carestream Dental LLC, Atlanta GA, USA). Standardized periapical radiographs were obtained using the long-cone paralleling technique (Kodak 2100230 V, Carestream Health Inc, Rochester, NY, $A B D$ ) and with position holders (Rinn XCP, Dentsply International) parameters set at $0.125 \mathrm{~s}$ exposure time, $60 \mathrm{Kv}$ and $70 \mathrm{~mA}$, at week 12. Images were transferred to computer by a photostimulable phosphor plate scanner (Digora ${ }^{\circledR}$ Optime, Soredex, USA).

CB levels on radiographic images were measured with a Java-based software (Image-J 3.0, NIH, Bethesda, ABD) by a calibrated examiner (GPT; Cronbach's alpha=0.99) who was masked to the groups. Radiographic sections of each implant were taken and assigned to respective coded folders by an 
unmasked investigator (AG) before measurements. Implant shoulder (IS), first bone to implant contact ( $\mathrm{fBIC}$ ), implant abutment interface (I) and apex of the implant (IA) were used as reference points (Figure 4). IS-fBIC distance at baseline, weeks 12 and 24 were measured. IS-fBIC distance at weeks 12 and 24 were deemed as corresponding bone loss values. All implants were subjected to place equicrestally. However, in a few cases due to uneven bone anatomy some aspects of the implants were placed subcrestally less than $1 \mathrm{~mm}$ in order to abstain from supracrestal positioning at baseline (mean subcrestal positioning was $0.05 \mathrm{~mm}$ in PS, $0.02 \mathrm{~mm}$ in drill groups). When this was the case, subcrestal positioning of IS as was revealed on baseline $\mathrm{CBCT}$ sections was added to the corresponding bone loss measurement. I-IA distance was used to calibrate the marginal bone level measurements. All distances were measured three-times, were averaged and the values were rounded to the nearest $0.01 \mathrm{~mm}$.

\section{Data analysis}

Minimum sample size was calculated using G*Power 3 (Fault et al. 2009) considering a difference of $0.5 \mathrm{~mm}$ in mean CB loss values and accepting a power of $80 \%$, p-value of $5 \%$ in study groups. Sample size calculation analysis revealed that the minimum required sample size was eighteen for each group. This estimate was based on a one-tailed test of matched pairs. To compensate probable dropouts the sample size was adjusted to 20. The primary outcome variable was selected as CB loss. PISF RANKL and OPG levels served as secondary outcome variables.

A statistician who was blinded to the groups performed statistical analysis using non-parametrical methods. The patient was used as the unit of analysis. The following hypothesis was tested: Alteration of the CB levels and OPG and RANKL levels and RANKL/OPG ratio and changes in PD, MPI, MGI, PISF volume and VAS scores is dependent on preparation method of osteotomy (piezosurgery vs drilling) and time after surgery, as tested with the nonparametric model of Brunner and Langer using a web-based software ( $R$ software, version 3.3.1, package: nparLD, R Foundation for Statistical Computing, Vienna, Austria; r- 
project.org). EHI scores were compared with McNemar-Bowker chi-square test. Calibration of the examiner was assessed by weighted kappa, and intraclass correlation coefficient methods for PD and radiological CB loss measurements, respectively. A statistical software was used for data analysis (SPSS 20.0, SPSS for Windows, SPSS Inc., Chicago, USA). $\alpha$ for statistical significance level was set at $5 \%$ for all analyses.

\section{Results}

\section{Demografic features and clinical data}

A total of 40 implants were placed to 15 subjects who had bilateral maxillary posterior edentulous sites $(4.1 \mathrm{~mm} \times 8 \mathrm{~mm}, \mathrm{n}=12 ; 4.1 \mathrm{~mm} \times 10 \mathrm{~mm}, \mathrm{n}=11$; 4.1 mm $\times 12 \mathrm{~mm}, \mathrm{n}: 15)$. In this split-mouth design 5 of the patients received 2, whereas the other 10 received 1 pair of implants. One patient was excluded from the study due to early loss of 2 implants due to chewing on the healing abutments; thus the 24-week study follow-up was completed with 38 implants in 14 patients (10 female, 4 male; Age range: 31-64; Mean age $\pm S D: 50.0 \pm 8.4$ ), corresponding to 19 implants (11 premolar, 8 molar sites) in each group. Baseline radiographic alveolar bone height values of the PS and drill groups were $13.05 \pm 2.2 \mathrm{~mm}$ and $13.31 \pm 2.5 \mathrm{~mm}$, respectively. Radiographic bone width at baseline was 7.91 \pm 0.7 and 7.85 $\pm 0.5 \mathrm{~mm}$ in PS and drill groups, respectively. Flow diagram of the study participants is outlined in Figure 5.

Mean full mouth PD, plaque and bleeding on probing scores of subjects at baseline were $2.07 \pm 0.18 \mathrm{~mm}, 6.89 \pm 2.60 \%$ and $6.75 \pm 3.08 \%$, respectively. Mucosa thickness and width of buccal keratinized mucosa at edentulous sites of PS and drill groups did not differ significantly $(3.4 \pm 0.7 \mathrm{~mm}$ vs $3.4 \pm 0.6 \mathrm{~mm} ; \mathrm{p}=0.96$ and $4.8 \pm 1.5 \mathrm{~mm}$ vs $\pm 4.8 \pm 1.6 \mathrm{~mm} ; \mathrm{p}=0.96$, respectively) ( $p>0.05)$.

Time spent for preparation of implant osteotomy was significantly higher in PS group than in the drill group ( $538.2 \pm 107.8$ vs $294.9 \pm 86.5 ; p=0.00005)$. Implants placed into osteotomies prepared with PS tips and drills did not show differences 
regarding insertion torque values $(49.2 \pm 3.4$ vs $49.2 \pm 3.4 ; p=0.99)$. None of the study sites showed evidence of edema, infection or bleeding at first and second week postoperative control visits. At these time intervals both groups exhibited undisturbed flap adaptation, as revealed by the EHI scores ( $1.4 \pm 0.7$ vs $1.5 \pm 0.8$ at week 1: $p=0.37$ and $1.1 \pm 0.3$ vs $1.2 \pm 0.4$ at week $2 ; p=0.99$, in PS and drill groups, respectively).

The differences between groups with regards to changes in PD measurements at weeks 12 and 24 did not depend on time $(p=0.64)$, treatment (i.e: method of osteotomy, $\mathrm{p}=0.07$ ) and interaction of time and treatment $(p=0.61)$ (Table 1). PD values of both groups were within the health limits (2.16 $\pm 0,52$ vs $2.44 \pm 0.53$ at week 12 ; and $2.26 \pm 0.52$ vs $2.39 \pm 0.49$ at week 24 ; in PS and drill groups, respectively).

MPI and MGI scores and PISF volume values of study groups during the course of the study are presented in Table 2. MPI score alteration depended on time $(p=2.63 e-11)$, but not on osteotomy method $(p=0.17)$ or interaction of time and method $(p=0.88)$ (Table 1). MPI score of both groups at 2 week was significantly higher than the scores measured at weeks 4, 8, 12 and 24 ( $p=2.02 e-$ 05, 1.26e-07, 3.02e-12 and 4.22e-15, respectively) (Table 2). As demonstrated by lack of a time effect $(p=0.16)$ and treatment effect $(p=0.21)$ MGI scores did not show any variation during the course of the follow-up period in study groups. However, interaction of time and treatment had $\mathrm{n}$ significant effect on MGI $(p=0.003)$ (Table 1). Changes in PISF volume were dependent on time $(p=3.54 \mathrm{e}-$ 07), but not on osteotomy method ( $\mathrm{p}=0.44)$ or interaction of time and treatment $(\mathrm{p}=0.38)$ (Table 1). PISF volume derived from sites prepared with PS and drils decreased at weeks 4, 8, 12 and 24 in comparison to week 2 ( $p=4.36 e-04,3.29 e-$ 05, 2.18e-10 and 5.32e-07, respectively) (Table 2).

VAS scores used to assess pain perception at sites of surgery are outlined in Table 3. VAS score changes in study groups depended on time $(p=4.87 e-11)$ and showed a decreasing trend compared to day of surgery (day 1) on days 2 and 7 ( $p=6.78 \mathrm{e}-06$ and $p=7.55 \mathrm{e}-12$, respectively). VAS score was found to be dependent to osteotomy method ( $\mathrm{p}=0.04$ ) which PS group had lower scores on days 2 and 7 
than the scores of the drill group ( $p=0.036$ and $p=0.015$, respectively) (Tables 1 and 3 ).

\section{Radiological crestal bone loss}

$\mathrm{CB}$ loss as was recorded by measuring the IS-fBIC distance on periapical radiograms at week 12 and on CBCT sections at week 24 are outlined in Table 4. CB loss values of PS and drill groups measured on mesial, distal and buccal aspects and average of proximal and all four aspects depended on time ( $p=0.001$, $0.005,0.004,3.36 \mathrm{e}-05$ and $5.92 . \mathrm{e}-06$, respectively) but this effect was not found to be significant for palatal aspects $(p=0.13)$. No significant treatment effect was detected regarding $C B$ loss except for a significant effect on mesial aspects in favour of PS group $(p=0.04)$ CB loss was not dependent to interaction of time and treatment on single, proximal or overall values (Table 1).

\section{PISF RANKL and OPG levels and RANKL/OPG ratio}

RANKL total amount levels, RANKL concentration, OPG total, OPG concentration and RANKL/OPG ratio in PISF samples are outlined in Table 4. RANKL total amount levels, RANKL concentration, OPG total, OPG concentration and RANKL/OPG ratio depended on time ( $p=4.69 \mathrm{e}-09$, 0.006, 1.89e-08, 5.80e-22 and 2.51e-10, respectively). No significant effect of time and treatment interaction was observed for PISF levels of RANKL total amount, RANKL concentration, OPG total, OPG concentration and for RANKL/OPG ratio ( $p=0.67$, $0.57,0.23,0.12$ and 0.35 , respectively). RANKL total levels that were lower in PS group depended on osteotomy method $(p=0.02)$ (Table 1$)$.

Week 4, 8, 12 and 24 values of RANKL total and RANKL/OPG ratio decreased compared to week 2 in study groups ( $\mathrm{p}=0.0002,1.09 \mathrm{e}-07,1.28 \mathrm{e}-13$ and 2.88e-06, respectively for RANKL total and $\mathrm{p}=0.001,1.82 \mathrm{e}-06,1.06 \mathrm{e}-10$ and $2.85 \mathrm{e}-08$, respectively for RANKL/OPG). In a similar manner at weeks 4, 8, 12 and 24 OPG concentration elevated in comparison to week 2 levels (0.002, 8.56e-09, 1.91e-18

and $5.35 \mathrm{e}-14$, respectively) whereas total amount of OPG showed this increasing trend at weeks 8, 12 and $24(p=0.0004,4.04 \mathrm{e}-06$ and 1.22e-08). Intragroup 
comparisons revealed that RANKL concentration did not change significantly over the follow-up period (Table 5).

\section{Discussion}

The present study was undertaken to compare the effects of PS and conventional drill osteotomy on bone healing process and early CB loss related to creation of an osteotomy by referring to biochemical and radiological parameters. Since early CB loss is dependent on multitude of factors, in order to solely determine the effects of osteotomy modality on CB loss, an attempt to exclude, modify and standardize these factors was made in patient selection and study design.

Smoking is a factor that may influence early CB loss. No smokers were enrolled to the study since it has been demonstrated that smokers losed more CB than non-smokers in the period between placement of implants to the upper jaw and loading (Jeong et al. 2008). Another factor associated with early CB loss is the position of IS with reference to the bone crest (Cesaretti et al. 2014, Jung et al. 2008). In order to standardize the IS positions and increase the evaluation accuracy of most coronal part of CB in baseline radiological sections all implants were placed flush with bone. Accumulated evidence suggests in presence of a mucosa thickness less than 2 or $2.5 \mathrm{~mm} \mathrm{CB}$ occurs as a result of biological width establishment around implants (Puisys et al. 2013, Linkevicius et al. 2009). Preoperative evaluation of a mucosa thickness $\geq 3 \mathrm{~mm}$ and its confirmation intraoperatively allowed exclusion of CB loss related to biological width establishment. In addition, impairment of flap closure may negatively affect wound healing and CB levels around implants. Similar EHI values of study groups suggest the absence of compromised healing and related CB loss.

Maxillary posterior sites generally harbor bone with wide trabecular spaces and thinner cortical plate that results in enhanced cutting efficacy of PS. In maxilla the risk of complications related to increased heat and pressure with PS osteotomy is reduced due to low bone density (Stelzle et al. 2012). 
Furthermore, low-density bone allows preparation of implant osteotomy solely with consecutive PS implant tips without using crestall drills or bone taps. In addition, in order to create comparable osteotomy geometry both with PS tips and drills a parallel-walled drill and a PS tip system were selected. Therefore, 4.1 mm-wide non-tapered implants were placed into $3.5 \mathrm{~mm}$ parallel-walled osteotomies in the posterior maxilla in both PS and drill groups. However, final tip used for PS osteotomy was $0.2 \mathrm{~mm}$ narrower than the final drill. Therefore, for preparing analogous osteotomy geometry in both groups final diameter of the osteotomies were controlled with $3.5 \mathrm{~mm}$-wide parallelling pins. Similar insertion torque values in groups further confirmed the matching osteotomy diameters. However, this discrepancy between final tip and drill diameter may be one of the factors that may have caused longer osteotomy time in PS group.

In the present study mean proximal CB loss was $0.22 \mathrm{~mm}$ at the end of the 24 weeks in the drill group. A vast array of experimental and clinical studies have reported data regarding $\mathrm{CB}$ level changes around implants placed into osteotomies prepared with drills which occurred in the period between implant installation and time of loading. These studies have heterogenous design which comprises comparison and generally involves factors related to $\mathrm{CB}$ loss including systemic diseases, position of rough surface of implant relative to crest, implant design, smoking, jaw type, follow-up duration and CB measurement method. Therefore, to minimize contrasts $C B$ results of the present study were only compared with previous clinical trials that have investigated CB loss around implants in the upper jaw (Penarrocha-Diago et al. 2013, Jeong et al. 2008, Nickenig et al. 2010, Galindo-Moreno et al. 2014). Although these aforementioned studies differ in design they have reported mean proximal CB loss of 0.08-0.22 $\mathrm{mm}$ that was in line with the finding of our study (Jeong et al. 2008, Nickenig et al. 2010, Penarrocha-Diago et al. 2013, Galindo-Moreno et al. 2014). Two studies showing best agreement in design and $C B$ loss values are discussed. In a recent study, Galindo-Moreno et al. (2014) have showed $0.19 \mathrm{~mm} \mathrm{CB}$ loss around submerged, two-piece, internal-connection implants on panaromic radiographies 5 months after surgery. Similarly, Jeong et al. (2008) found that submerged, two- 
piece, platform-switched implants placed level with the crest lost $0.22 \mathrm{~mm} \mathrm{CB} 4$ months after surgery. The latter showed exact radiological CB loss with the present study. On the other hand, only one study utilized CBCT and reported preloading CB loss values up to date. In this study by Gültekin et al. (2013) two-piece, platform switch implants were placed to upper and lower jaws equicrestally. CB loss values avaraged from 4 aspects were $0.22 \mathrm{~mm}$ at 3 months following surgery that was in agreement with our CBCT finding, $0.12 \mathrm{~mm}$.

Mean CB loss revealed by CBCT was 0.11 and $0.12 \mathrm{~mm}$ at the end of the 24 weeks in the PS and drill groups, respectively. This finding may indicate that when patient, implant and surgery-based factors associated with CB loss before loading are controlled, the effect of osteotomy on CB loss is limited in maxilla, irrespective of the method utilized. This may be the result of high wound healing and repair capacity of maxillary posterior bone since it has abundant cell and vascular content (Davies 2003). Previous studies also reported lower CB loss values in maxilla than in mandible around un-loaded implants (Jeong et al. 2008, Nickenig et al. 2010, Penarrocha-Diago et al. 2013, Galindo-Moreno et al. 2014).

Following implant insertion in the mandible integration between implant surface and mineralized tissues is largely completed at $12^{\text {th }}$ week following formation of primary matrix and osteons, replacement of woven bone with lamellar bone and formation of secondary osteons and enhanced mineralization, respectively (Berglundh et al. 2003, Davies 2003). In the present study PISF samples were collected at weeks 2, 4, 8 and 12 weeks which corresponds to the above critical healing periods revealed in histological sections. In addition, considering the longer bone-healing period of maxilla PISF collection was extended up to week 24. This is the first study to address changes in RANKL-OPG system during osseointegration process. RANKL and RANKL/OPG decreased whereas OPG values increased during the course of osseointegration. Detectible limits of RANKL and OPG at all time points may indicate that RANKL-OPG system is one of the key bone remodeling mechanisms involved in establishment of a biological connection between implant and bone.

PS group exhibited lower RANKL levels than the drill group suggesting 
decreased osteoclastic activity. This finding is supported by observations from a study that has shown lower number of inflammatory cells, higher number of osteoblasts, increased expression of BMP-4 and TGF-beta 2, and lower expression of proinflammatory cytokines in the PS group than drill group following implant osteotomy (Preti et al. 2007). Recent reports have demonstrated higher stability of implants and limited decrease of primary stability of implants placed following PS osteotomy, compared to drill osteotomy during osseointegration period (Stacchi et al. 2013, Canullo et al. 2013, da silva Neto et al. 2014). These results may collectively indicate faster bone healing and an earlier shifting from a decreasing to an increasing stability pattern in osteotomies prepared with PS than drills due to generation of less trauma. Lower pain perception at the day of surgery might further confirm the advantageous feature of PS over drills. However, these advantages did not result in significant differences in overall CB loss values.

Findings of the present study suggested that PS osteotomy in maxillary posterior region is similar to drill osteotomy in terms of CB bone loss. PS seems to have potential to modify bone resorption mechanisms and reduce inflammatory response during osseointegration and be a less traumatic osteotomy modality than drilling although this is not reflected by CB loss values. This is the first study to demonstrate the effect of consecutive use of PS osteotomy tips on CB loss. CB loss related to osteotomy solely prepared with PS should be evaluated by further clinical trials incorporating different PS tip and implant designs, anterior maxillary and mandibular sites and other biochemical markers.

\section{Acknowledgement}

The authors wish to thank to Biodenta for providing implants and suprastructures and to Drs., Pelin Güneri, Gülnur Emingil and Bülent Gökçe for their valuable contributions to the study. This study was supported by grants from Ege University Research Fund (BAP 2013/Dent/009) and institutional funds from the University of Zürich. The authors would like to thank Mrs. Elpida Plattner for her technical assistance with the ELISA assays. 


\section{References}

Alberti, L. D., Donnini, F., Alberti, C. D. \& Camerino, M. (2010) A comparative study of bone densitometry during osseointegration: piezoelectric surgery versus rotary protocols. Quintessence International 41: 639-644.

Annibali, S., Bignozzi, I., Monaca, G. L., Cristalli, M. P. (2012) Usefulness of the aesthetic result as a success criterion for implant therapy: a review. Clinical Implant Dentistry and Related Research 14: 3-40.

Baker, J. A., Vora, S.,20Bairam, L., Kim, H. I., Elaine, L. D. \& Andreana, S. (2012) Piezoelectric versus conventional implant site preparation: ex vivo implant primary stability. Clinical Oral Implants Research 23: 433-437.

Belibasakis, G.N. \& Bostanci, N. (2012) The RANKL-OPG system in clinical periodontology. Journal of Clinical Periodontology 39:239-248.

Bengazi, F., Lang, N. P., Canciani, E., Vigano, P., Urbizo, V. J. \& Botticelli, D. (2014) Osseointegration of implants with dendrimers surface characteristics installed conventionally or with piezosurgery: a comparative study in the dog. Clinical Oral Implants Research 25: 10-15.

Berglundh, T., Abrahamsson, I., Lang, N.P. \&2 [Lindhe, J. (2003) De novo alveolar bone formation adjacent to endosseous implants. A model study in the dog.?Clinical Oral Implants Research 14: 251-262.

Canullo, L., Penarrocha, D., Penarrocha, M., Rocio, A. G. \& Penarrocha-Diago, M. (2013) Piezoelectric vs. conventional drilling in implant site preparation: pilot controlled randomized clinical trial with crossover design.? ?Clinical Oral Implants Research 25: 13361343.

Capelli, M. (2013) Surgical, biologic and implant related factors affecting bone remodeling around implants. European Journal of Esthetic Dentistry 8: 279-313.

Chiriac, G., Herten, M., Schwarz, F., Rothamel, D. \& Becker, J. (2005) Autogenous bone chips: influence of a new piezoelectric device (Piezosurgery) on chip morphology, cell viability and differentiation. Journal of Clinical Periodontology 32: 994-999.

Claire, S., Lea, S.C. \& Walmsley, A.D. (2013) Characterisation of bone following ultrasonic cutting. Clinical Oral Investigations 17: 905-912. 
da Silva Neto, U.T., Joly, J.C. \& Gehrke, S.A. (2014) Clinical analysis of the stability of dental implants after preparation of the site by conventional drilling or piezosurgery. British Journal of Oral and Maxillofacial Surgery 52 :149-53.

Davies, J.E. (2003) Understanding peri-implant endosseous healing. Journal of Dental Education 67: 932-49.

Esteves, J.C., Marcantonio, J.E., de Souza Faloni, A.P., Rocha, F.R., Marcantonio, R.A., Wilk, K. \& Intini, G. (2013) Dynamics of bone healing after osteotomy with piezosurgery or conventional drilling - histomorphometrical, immunohistochemical, and molecular analysis. Journal of Translational Medicine 11:-221.

Faul, F., Erdfelder, E., Buchner. A. \& Lang. A.G (2009). Statistical power analyses using G*Power 3.1: tests for correlation and regression analyses. Behav Res Methods 41:11491160.

Galindo-Moreno, P., León-Cano, A., Ortega-Oller, I., Monje, A., O-Valle, F. \& Catena, A. (2014) Marginal bone loss as success criterion in implant dentistry: beyond $2 \mathrm{~mm}$.?Clinical Oral Implants Research 2014 Jan 3. doi: 10.1111/clr.12324. [Epub ahead of print]

Gultekin, B. A., Gultekin, P., Leblebicioglu, B., Basegmez, C. \& Yalcin, S. (2013) Clinical evaluation of marginal bone loss and stability in two types of submerged dental implants. International Journal of Oral Maxillofacial Implants 28: 815-823.

Jeong, S. M., Choi, B. H., Li, J., Ahn, K. M., Lee, S. H. \& Xuan, F. (2008) Bone healing around implants following flap and mini-flap surgeries: a radiographic evaluation between stage I and stage II surgery. Oral Surgery, Oral Medicine, Oral Pathology, Oral Radiology, and Endodontology 105: 293-296.

Jung, R.E., Jones, A.A., Higginbottom, F.L., Wilson, T.G., Schoolfield, J., Buser, D., Hammerle, C.H.F. \& Cochran, D.L. (2008) The influence of non-matching implant and abutment diameters on radiographic crestal bone levels in dogs. Journal of Periodontology 79: 260-270.

Kfouri, F.A., Duailibi, M. T., Bretos. J. L. G., Carvalho, A.B., Pallos, D. \& Duailibi, S.E. (2013) Piezoelectric osteotomy for the placement of titanium implants in rabbits: histomorphometry study. Clinical Oral Implants Research 25: 1182-1188.

Linkevicius, T., Apse, P., Grybauskas, S. \& Puisys, A. (2009) The influence of soft tissue thickness on crestal bone changes around implants: a 1-year prospective controlled clinical trial. International Journal of Oral Maxillofacial Implants 24: 712-709. 
Maurer, P., Kriwalsky, M. S., Veras, R. B., Vogel, J., Syrowatka, F. \& Heiss, C. (2008) Micromorphometrical analysis of conventional osteotomy techniques and ultrasonic osteotomy at the rabbit skull. Clinical Oral Implants Research 19: 570-575.

Nickenig, H. J., Wichmann, M., Schlegel, K. A., Nkenke, E. \& Eitner, S. (2010) Radiographic evaluation of marginal bone levels during healing period, adjacent to parallel-screw cylinder implants inserted in the posterior zone of the jaws, placed with flapless surgery. Clinical Oral Implants Research 21: 1386-1393.

Oh, T.J., Yoon, J., Misch, C.E. \& Wang, H.L. (2002) The causes of early implant bone loss: myth or science. Journal of Periodontology 73: 322-333.

Padmanabhan, T.V. \& Gupta, R. (2010) Comparison of crestal bone loss and implant stability among implants placed with conventional procedure and using osteotome technique: clinical study. Journal of Oral Implantology 36: 475-483.

Papaspyridakos, P., Chen, C.J., Singh, M., Weber, H.P. \& Gallucci, G.O. (2012) Success criteria in implant dentistry: a systematic review. Journal of Dental Research 91: 242-248.

Pavlikova, G., Foltan, R., Horka, M., Hanzelka, T., Borunska, H. \& Sedy, J. (2011) Piezosurgery in oral and maxillofacial surgery. International Journal of Oral Maxillofacial Surgery 40: 451-457.

Penarrocha-Diago, M.A., Flichy-Fernandez, A.J., Alonso- Gonzalez, R., Penarrocha-Oltra, D., Balaguer-Martınez, J. \& Penarrocha-Diago, M. (2013) Influence of implant neck design and implant-abutment connection type on peri-implant health. Radiological study.?Clinical Oral Implants Research 24: 1192-1200.

Preti, G., Martinasso, G., Peirone, B., Navone, R., Manzella, C., Muzio, G., Russo, C., Canuto, R.A. \& Schierano, G. (2007) Cytokines and growth factors involved in the osseointegration of oral titanium implants positioned using piezoelectric bone surgery versus a drill technique: a pilot study in minipigs. Journal of Periodontology 78: 716-722.

Puisys, A. \& Linkevicius, T. (2013) The influence of mucosal tissue thickening on crestal bone stability around bone-level implants. A prospective controlled clinical trial.?Clinical Oral Implants Research 26: 123-129.

Rashad, A., Kaiser, A., Prochnow, N., Schmitz, I., Hoffmann, E., Maurer, P. Heat production during different ultrasonic and conventional osteotomy preparations for dental implants. Clinical Oral Implants Research 22: 1361-1365.

Schlee, M., Steigmann, M., Bratu, E. \& Garg, A.K. (2006) Piezosurgery: basics and 
possibilities. Implant Dentistry 15: 334-340.

Schütz, S., Egger, J., Kühl, S., Filippi, A. \& Lambrecht, J.T. (2012) Intraosseous temperature changes during the use of piezosurgical inserts in vitro. International Journal of Oral and Maxillofacial Surgery 41: 1338-43.

Shayesteh, Y. S., Khojasteh, A., Siadat, H., Monzavi, A., Bassir, S.H., Hossaini, M. \& Alikhasi, M. (2013) A comparative study of crestal bone loss and implant stability between osteotome and conventional implant insertion techniques: a randomized controlled clinical trial study. Clinical Implant Dentistry and Related Research 15: 350-357.

Stacchi, C., Vercellotti, T., Torelli, L., Furlan, F. \& Di Lenarda, R. (2013) Changes in implant stability using different site preparation techniques: twist drills versus piezosurgery. A single-blinded, randomized, controlled clinical trial. Clinical Implant Dentistry and Related Research 15: 188-197.

Stelzle, F., Neukam, F. W., Nkenke, E. (2012) Load dependent heat development, thermal effects, duration and soft tissue preservation in piezosurgical implant site preparation: an experimental ex vivo study. International Journal of Oral Maxillofacial Implants 27: 513522.

Tatarakis, N., Bashutski, J., Wang, H. L. \& Oh, T.J. (2012) Early implant bone loss: preventable or inevitable. Implant Dentistry 21: 379-386.

Trisi, P., Carlesi, T., Colagiovanni, M., Falco, A., Bovi, M. \& Perfetti, G. (2011) Ultrasonic vs drill osteotomy.A clinical and histologic study in the sheep mandible. Journal of Osteology and Biomaterials 2: 21-31.

Vercellotti, T., Stacchi, C., Russo, C., Rebaudi, A., Vincenzi, G., Pratella, U., Baldi, D., Mozzati, M., Monagheddu, C., Sentineri, R., Cuneo, T., Di Alberti, L., Carossa, S. \& Schierano, G. (2014) Ultrasonic implant site preparation using piezosurgery: a multicenter case series study analyzing 3,579 implants with a 1- to 3-year follow-up. International Journal of Periodontics and Restorative Dentistry 34: 11-18.

Wachtel, H., Schenk, G., Bohm, S., Weng, D., Zuhr, O., Hurzeler, M.B. (2003) Microsurgical access flap and enamel matrix derivative for the treatment of periodontal intrabony defects: a controlled clinical study. Journal of Clinical Periodontology 30: 496504. 
Table 1: Effect of time (intragroup comparisons), treatment (intergroup comparison of osteotomy modality) and time $x$ treatment interaction on radiological, biochemical and clinical parameters.

\begin{tabular}{|c|c|c|c|}
\hline \multirow[b]{2}{*}{ Variables } & \multicolumn{3}{|c|}{$\begin{array}{l}\text { ANOVA-type statistics according to } \\
\text { Brunner-Langer method }\end{array}$} \\
\hline & $\begin{array}{c}\text { Time } \\
\text { effect } \\
P=\end{array}$ & $\begin{array}{c}\text { Treatment } \\
\text { effect } \\
\mathrm{P}=\end{array}$ & $\begin{array}{c}\text { Time } \mathrm{x} \\
\text { treatment } \\
\text { interaction } \\
\mathrm{P}=\end{array}$ \\
\hline \multicolumn{4}{|l|}{ CB loss } \\
\hline Mesial & 0.001 & 0.04 & 0.32 \\
\hline Distal & 0.005 & 0.43 & 0.48 \\
\hline Buccal & 0.004 & 0.62 & 0.53 \\
\hline Palatal & 0.13 & 0.54 & 0.97 \\
\hline Mesial \& Distal & $3.36 e-05$ & 0.25 & 0.55 \\
\hline Mesial, Distal, Buccal, Palatal & $5.92 e-06$ & 0.60 & 0.91 \\
\hline RANKL total & 4.69e-09 & 0.02 & 0.67 \\
\hline RANKL concentration & 0.006 & 0.54 & 0.57 \\
\hline OPG total & $1.89 \mathrm{e}-08$ & 0.72 & 0.23 \\
\hline OPG concentration & $5.80 e-22$ & 0.48 & 0.12 \\
\hline RANKL/OPG & $2.51 \mathrm{e}-10$ & 0.19 & 0.35 \\
\hline$P D$ & 0.64 & 0.07 & 0.61 \\
\hline MPI & $2.63 \mathrm{e}-11$ & 0.17 & 0.88 \\
\hline MGI & 0.16 & 0.21 & 0.003 \\
\hline PISF & $3.54 \mathrm{e}-07$ & 0.44 & 0.38 \\
\hline VAS & $4.87 e-11$ & 0.04 & 0.59 \\
\hline
\end{tabular}


Table 2: MPI and MGI scores and PISF volume values of study groups during the course of the study.

\begin{tabular}{|c|c|c|c|c|c|}
\hline & & \multicolumn{2}{|c|}{ Piezosurgery } & \multicolumn{2}{|c|}{ Drill } \\
\hline & Weeks & Mean \pm SD & Median & Mean $\pm S D$ & Median \\
\hline \multirow{5}{*}{ MPI } & Week 2 & $0.89 \pm 0.64$ & 1 & $0.80 \pm 0.60$ & 1 \\
\hline & Week 4 & $0.42 \pm 0.63$ & 0 & $0.29 \pm 0.36$ & 0 \\
\hline & Week 8 & $0.34 \pm 0.62$ & 0 & $0.17 \pm 0.37$ & 0 \\
\hline & Week 12 & $0.11 \pm 0.32$ & 0 & $0.05 \pm 0.23$ & 0 \\
\hline & Week 24 & $0.05 \pm 0.23$ & 0 & 0 & 0 \\
\hline \multirow{5}{*}{ MGI } & Week 2 & $0.05 \pm 0.23$ & 0 & $0.22 \pm 0.35$ & 0 \\
\hline & Week 4 & $0.01 \pm 0.06$ & 0 & 0 & 0 \\
\hline & Week 8 & $0.03 \pm 0.11$ & 0 & $0.01 \pm 0.06$ & 0 \\
\hline & Week 12 & 0 & 0 & $0.03 \pm 0.11$ & 0 \\
\hline & Week 24 & $0.05 \pm 0.10$ & 0 & $0.01 \pm 0.06$ & 0 \\
\hline \multirow{5}{*}{$\begin{array}{l}\text { PISF } \\
\text { volume }\end{array}$} & Week 2 & $0.44 \pm 0.25$ & 0.42 & $0.54 \pm 0.22$ & 0.55 \\
\hline & Week 4 & $0.35 \pm 0.16$ & 0.28 & $0.38 \pm 0.17$ & 0.35 \\
\hline & Week 8 & $0.32 \pm 0.13$ & 0.31 & $0.29 \pm 0.14$ & 0.28 \\
\hline & Week 12 & $0.16 \pm 0.07$ & 0.15 & $0.21 \pm 0.09$ & 0.21 \\
\hline & Week 24 & $0.24 \pm 0.13$ & 0.22 & $0.24 \pm 0.08$ & 0.25 \\
\hline
\end{tabular}

MPI (Intragroup comparisons): $2 \mathrm{w}-4 \mathrm{w} \mathrm{p}=2.02 \mathrm{e}-05,2 \mathrm{w}-8 \mathrm{w} \quad \mathrm{p}=1.26 \mathrm{e}-07,2 \mathrm{w}-12 \mathrm{w}$ $\mathrm{p}=3.02 \mathrm{e}-12$ and $2 \mathrm{w}-24 \mathrm{w} \mathrm{p}=4.22 \mathrm{e}-15$.

PISF volume (Intragroup comparisons): $2 w-4 w p=4.36 e-04,2 w-8 w p=p=3.29 e-05$, $2 w-12 w p=2.18 e-10$ and $2 w-24 w p=5.32 e-07$. 
Table 3: VAS scores used to assess pain perception at surgery sites.

\begin{tabular}{|c|c|c|c|c|c|}
\hline & \multicolumn{2}{|c|}{ Piezosurgery } & \multicolumn{2}{c|}{ Drill } & $\begin{array}{c}\text { Piezosurgery } \\
\text { vs Drill }\end{array}$ \\
\hline & Mean \pm SD & Median & Mean \pm SD & Median & P= \\
\hline Day 1 & $20.3 \pm 20.1$ & 12 & $28.9 \pm 26.7$ & 14 & 0.002 \\
\hline Day 2 & $12.0 \pm 12.3$ & 11 & $15.5 \pm 18.2$ & 11 & 0.154 \\
\hline Day 7 & $4.5 \pm 7.0$ & 1 & $5.7 \pm 7.2$ & 1 & 0.050 \\
\hline
\end{tabular}

VAS (Intragroup comparisons): Day 1 -Day $2 ; p=6.78 \mathrm{e}-06$, Day 1 - Day $7 ; p=7.55 e-$ 12, Day 2 - Day 7; $p=7.59 \mathrm{e}-05$. 
Table 4: Crestal bone loss levels (IS-fBIC distance) on periapical radiograms at week 12 and on CBCT sections at week 24 .

\begin{tabular}{|c|c|c|c|c|c|}
\hline & & \multicolumn{2}{|c|}{ Piezosurgery } & \multicolumn{2}{|c|}{ Drill } \\
\hline Time & Implant aspect & Mean \pm SD & Median & Mean \pm SD & Median \\
\hline \multirow{3}{*}{ Week 12} & Mesial & $0.07 \pm 0.26$ & 0 & $0.14 \pm 0.35$ & 0 \\
\hline & Distal & $0.13 \pm 0.23$ & 0 & $0.12 \pm 0.31$ & 0 \\
\hline & Mesial and Distal & $0.11 \pm 0.23$ & 0 & $0.18 \pm 0.33$ & 0 \\
\hline \multirow{6}{*}{ Week 24} & Buccal & $0.08 \pm 0.25$ & 0 & $0.02 \pm 0.09$ & 0 \\
\hline & Mesial & $0.16 \pm 0.33$ & 0 & $0.27 \pm 0.41$ & 0.27 \\
\hline & Distal & $0.15 \pm 0.32$ & 0 & $0.17 \pm 0.36$ & 0 \\
\hline & Palatal & $0.07 \pm 0.23$ & 0 & $0.01 \pm 0.10$ & 0 \\
\hline & Mesial and Distal & $0.15 \pm 0.24$ & 0 & $0.22 \pm 0.33$ & 0.15 \\
\hline & Buccal, Mesial, Distal and Palatal & $0.11 \pm 0.20$ & 0 & $0.12 \pm 0.16$ & 0.10 \\
\hline
\end{tabular}


Table 5: PISF RANKL and OPG levels.

\begin{tabular}{|c|c|c|c|c|c|}
\hline & & \multicolumn{2}{|c|}{ Piezosurgery } & \multicolumn{2}{|c|}{ Drill } \\
\hline & Weeks & Mean \pm SD & Median & Mean \pm SD & Median \\
\hline \multirow{5}{*}{$\begin{array}{l}\text { RANKL total } \\
\text { (pg/4sites) }\end{array}$} & Week 2 & $73.28 \pm 54.8$ & 62.7 & $80.36 \pm 24.2$ & 81.6 \\
\hline & Week 4 & $56.45 \pm 43.0$ & 48.3 & $59.78 \pm 25.7$ & 59.7 \\
\hline & Week 8 & $52.26 \pm 55.8$ & 35.4 & $53.53 \pm 51.7$ & 42.7 \\
\hline & Week 12 & $42.57 \pm 28.2$ & 33.9 & $42.30 \pm 25.8$ & 45.1 \\
\hline & Week 24 & $51.61 \pm 29.4$ & 56.4 & $57.2 \pm 22.1$ & 62.9 \\
\hline \multirow{5}{*}{$\begin{array}{l}\text { RANKL } \\
\text { concentration } \\
(\mathrm{pg} / \mu \mathrm{l})\end{array}$} & Week 2 & $60.87 \pm 54.9$ & 41.8 & $46.22 \pm 44.2$ & 36.0 \\
\hline & Week 4 & $56.03 \pm 67.9$ & 33.7 & $46.22 \pm 30.8$ & 37.6 \\
\hline & Week 8 & $46.3 \pm 47.9$ & 34.3 & $64.53 \pm 90.5$ & 33.1 \\
\hline & Week 12 & $86.3 \pm 79.6$ & 57.9 & $54.4 \pm 41.7$ & 49.9 \\
\hline & Week 24 & $75.2 \pm 62.1$ & 65.4 & $63.73 \pm 32.1$ & 66.5 \\
\hline \multirow{5}{*}{$\begin{array}{l}\text { OPG total } \\
\text { (pg/4 sites) }\end{array}$} & Week 2 & $12.04 \pm 9.3$ & 9.44 & $10.15 \pm 7.9$ & 7.68 \\
\hline & Week 4 & $17.95 \pm 18.8$ & 11.29 & $12.75 \pm 9.1$ & 11.7 \\
\hline & Week 8 & $26.53 \pm 29.9$ & 15.63 & $24.43 \pm 23.5$ & 19.25 \\
\hline & Week 12 & $27.12 \pm 29.1$ & 15.01 & $34.73 \pm 34.1$ & 23.73 \\
\hline & Week 24 & $24.07 \pm 18.3$ & 18.70 & $34.30 \pm 33.8$ & 26.3 \\
\hline \multirow{5}{*}{$\begin{array}{l}\text { OPG } \\
\text { concentration } \\
(\mathrm{pg} / \mu \mathrm{l})\end{array}$} & Week 2 & $9.46 \pm 9.4$ & 4.12 & $5.37 \pm 3.9$ & 5.00 \\
\hline & Week 4 & $13.49 \pm 9.4$ & 11.78 & $11.15 \pm 14.3$ & 5.85 \\
\hline & Week 8 & $32.30 \pm 54.6$ & 15.19 & $27.27 \pm 32.7$ & 16.45 \\
\hline & Week 12 & $72.59 \pm 112.8$ & 29.16 & $48.43 \pm 55.1$ & 28.98 \\
\hline & Week 24 & $35.32 \pm 36.1$ & 22.2 & $41.23 \pm 52.1$ & 26.79 \\
\hline \multirow{5}{*}{ RANKL/OPG } & Week 2 & $2.25 \pm 2.8$ & 1.62 & $2.68 \pm 2.1$ & 2.81 \\
\hline & Week 4 & $0.93 \pm 0.8$ & 0.68 & $1.72 \pm 1.5$ & 2.23 \\
\hline & Week 8 & $1.34 \pm 2.6$ & 0.85 & $1.07 \pm 1.5$ & 1.47 \\
\hline & Week 12 & $1.71 \pm 5.2$ & 0.62 & $2.42 \pm 8.2$ & 0.94 \\
\hline & Week 24 & $0.76 \pm 0.7$ & 0.67 & $0.67 \pm 0.6$ & 0.59 \\
\hline
\end{tabular}

RANKL total amount (Intragroup comparisons): $2 \mathrm{w}-4 \mathrm{w} p=0.0002,2 \mathrm{w}-8 \mathrm{w} p=1.09 \mathrm{e}-$ $07,2 w-12 w p=1.28 e-13,2 w-24 w p=2.88 e-06$.

OPG total amount (Intragroup comparisons): $2 \mathrm{w}-8 \mathrm{w} \mathrm{p}=0.0004,2 \mathrm{~W}-12 \mathrm{~W} \mathrm{p}=4.04 \mathrm{e}-$ $06,2 w-24 w p=1.22 e-08$.

OPG concentration (Intragroup comparisons): $2 \mathrm{w}-4 \mathrm{w}$ p $=0.002,2 \mathrm{w}-8 \mathrm{w} \mathrm{p}=8.56 \mathrm{e}-$ 09, 2w-12w p=1.91e-18, 2w-24w $p=5.35 \mathrm{e}-14$.

RANKL/OPG (Intragroup comparisons): $2 \mathrm{w}-4 \mathrm{w} p=0.001,2 \mathrm{w}-8 \mathrm{w} \mathrm{p}=1.82 \mathrm{e}-06,2 \mathrm{w}-$ $12 w p=1.06 e-10,2 w-24 w p=2.85 e-08$. 
Figure 1: Study outline

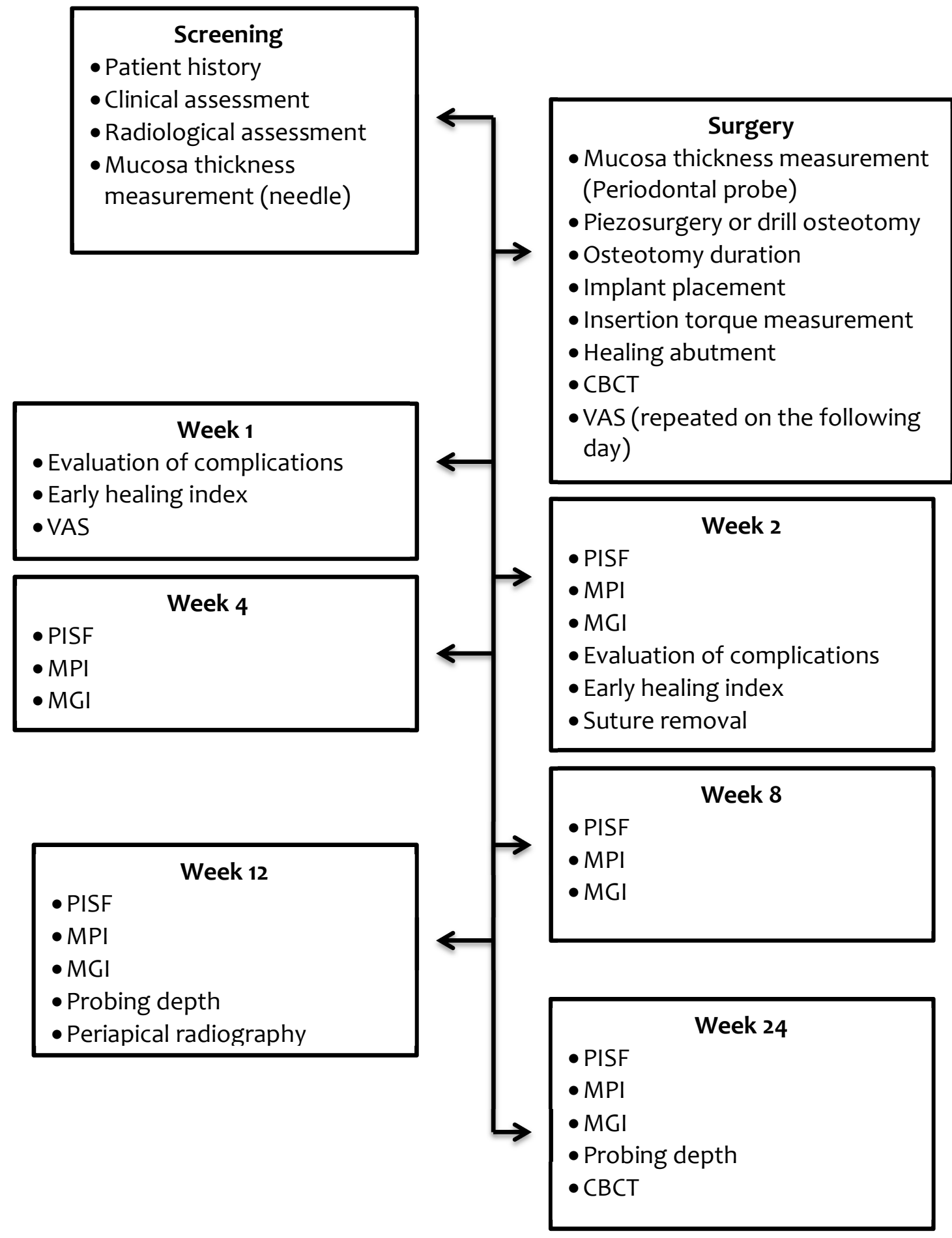


Figure 2: Clinical view of $3.5 \mathrm{~mm}$-wide osteotomy preparation for $4.1 \mathrm{~mm}$ diameter implant in the drill group: $2.0 \mathrm{~mm}$ pilot drill (a), control of depth, diameter and direction of initial osteotomy with $2.0 \mathrm{~mm}$ paralleling pin (b), $2.8 \mathrm{~mm}$ drill (c), $2.8 \mathrm{~mm}$ paralleling pin (d), $3.5 \mathrm{~mm}$ drill (e), control of final diameter of the osteotomy with $3.5 \mathrm{~mm}$ paralleling $\operatorname{pin}(f)$. 
Figure 3: Clinical view of $3.5 \mathrm{~mm}$-wide osteotomy preparation for $4.1 \mathrm{~mm}$ diameter implant in the piezosurgery group: $1.15 \mathrm{~mm}$ initial MB1 tip (a), $1.95 \mathrm{~mm} \mathrm{MB2}$ tip (b) control of depth, diameter and direction of osteotomy with $2.0 \mathrm{~mm}$ paralleling pin (c), $2.5 \mathrm{~mm}$ MB3 tip (d), $2.8 \mathrm{~mm} \mathrm{MB4}$ tip (e), $2.8 \mathrm{~mm}$ paralleling pin (f), $3.05 \mathrm{~mm} \mathrm{MB5}$ tip (g) $3.3 \mathrm{~mm}$ MB6 tip (h), control of final diameter of the osteotomy with $3.5 \mathrm{~mm}$ paralleling pin (i). 
Figure 4: Reference points used for radiographic assessment of marginal bone loss: Implant shoulder (IS), first bone to implant contact (fBIC), implant abutment interface (I) and apex of the implant (IA). 
Figure 5: Flowchart of study participants

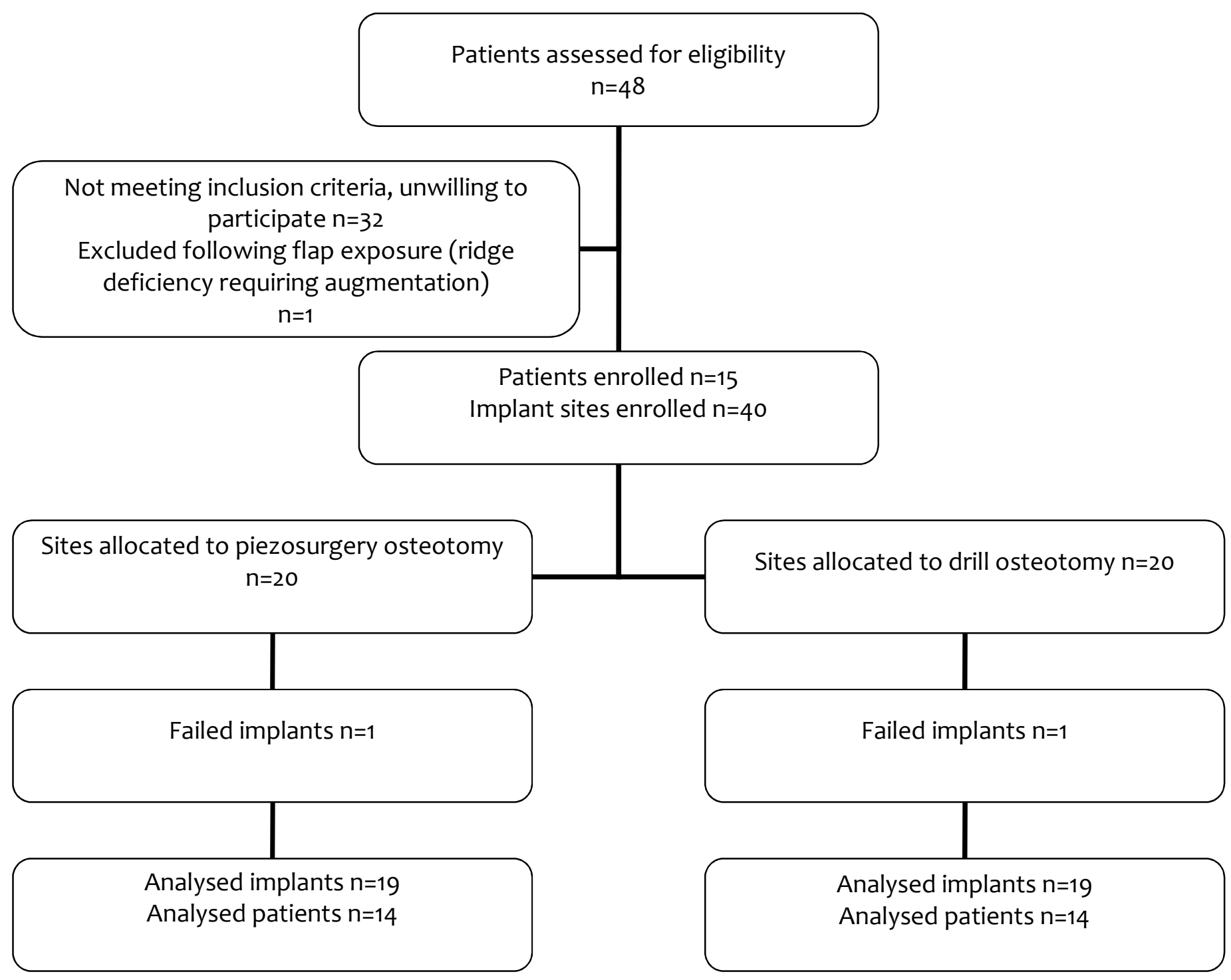


Figure 6: PISF RANKL and OPG levels. A) PISF RANKL total amount. " $\mathrm{p}<0.05$, significantly higher than week $12 .{ }^{\mathrm{b}} \mathrm{p}<0.05$, significantly higher than weeks 8,12 and 24 . B) PISF RANKL concentration. C) PISF OPG total amount. ${ }^{a} \mathrm{p}<0.05$, significantly lower than weeks 8, 12 and 24. D) PISF OPG concentration. ${ }^{a} \mathrm{p}<0.05$, significantly lower than weeks 12 and $24 .{ }^{b} \mathrm{p}<0.05$, significantly lower than weeks 8,12 and $24 .{ }^{c} \mathrm{p}<0.05$, significantly higher than week $4 .{ }^{\mathrm{d}} \mathrm{p}<0.05$, significantly higher than the drill group. E) PISF RANKL/OPG ratio. ${ }^{a} \mathrm{p}<0.05$, significantly higher than weeks 12 and $24 .{ }^{b} \mathrm{p}<0.05$, significantly lower than week $4 .^{c} p<0.05$, significantly higher than the piezosurgery group. Box plots represents medians as lines, $25^{\text {th }}$ and $75^{\text {th }}$ percentiles as boxes, $10^{\text {th }}$ and $90^{\text {th }}$ percentiles as whiskers and outliers as closed circles. (Bonferroni correctedWilcoxon test). 